\title{
PRESENTACIÓN DE LA EDICIÓN
}

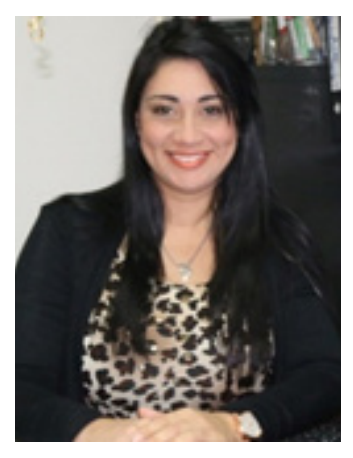

Magdy De las Salas Barroso

Editora de la Revista ORATORES

oratores@umecit.edu.pa

La Universidad Metropolitana de Educación, Ciencia y Tecnología (UMECIT), se complace en presentarles nuestra edición número 9 de la Revista ORATORES, correspondiente a Diciembre 2018 - Mayo 2019.

Abrir espacios para la divulgación del conocimiento científico, sigue siendo uno de los objetivos de la UMECIT a través de sus publicaciones. Nos complace poder brindar a nuestros lectores esta ventana de enriquecimiento profesional, actualización permanente y ser una alternativa para la socialización y transferencia de conocimiento, generado desde diversos rincones de la geografía latinoamericana

En esta edición presentamos un total de seis publicaciones de la pluma de investigadores nacionales e internacionales.

Iniciamos con el artículo de investigación titulado "Análisis situacional de los manuales de convivencia escolar en las instituciones educativas distritales de la localidad San Cristóbal de Bogotá" que presenta Cornelio Alexander Muñoz, de la Institución Educativa Distrital José Joaquín Castro Martínez de Bogotá D.C., Colombia y actualmente doctorando en Ciencias de la Educación de la UMECIT. En el documento el autor plantea conceptos y aportes sobre convivencia escolar y clima escolar, desde la perspectiva de diversos autores especialistas en la temática. Luego se hace una descripción de la situación actual de la convivencia escolar en algunas instituciones educativas oficiales de la localidad objeto de estudio.

El artículo presentado por el investigador Osvaldo Solís, adscrito a la Universidad Metropolitana de Educación, Ciencia y Tecnología, UMECIT, sede Chitré, titulado "Estudio para el establecimiento de una planta de recuperación y tratamiento de desechos sólidos urbanos en el Municipio de Chitré", el cual presenta entre sus conclusiones que gran parte de la población del municipio de Chitré, tienen conocimiento de los problemas que representa el vertedero para la comunidad y el ambiente; el total de los habitantes encuestados consideran indispensable, el reciclaje de los desechos sólidos urbanos; la gran mayoría de los habitantes encuestados están de acuerdo con la instalación de una planta de 
recuperación y tratamiento de residuos sólidos urbanos, en el municipio de Chitré.

El artículo de investigación de Elvia Lacera Padilla, de la Institución Educativa Distrital Simón Rodríguez, Colombia; Marcos Orellana Parra, Universidad Católica de Cuencas. Ecuador; Gonzalo Gustavo Cortez, Universidad Laica Eloy Alfaro de Manabí, Ecuador, titulado "Tecnología de la información y comunicación como herramienta para la toma de decisiones en las instituciones educativas en Santa Marta, Colombia", analiza la tecnología de la información y la comunicación (TIC) como herramienta para la toma de decisiones en las instituciones educativas en Santa Marta, Colombia, con la finalidad de fomentar una transformación radical en el área educacional orientada al uso de las nuevas tecnologías de información y comunicación, que tanto para los directivos como los docentes ocupe un lugar destacado, con participación activa, fomente un compromiso ineludible de superación y competencia profesional, que les permita asumir retos y el mejoramiento en la toma de decisiones en los niveles directivos, impulsando una educación de calidad basado en sistemas innovadores en los aspectos gerenciales y educativos.

El artículo realizado por Rosa María Aguirre, titulado "Desarrollo de habilidades sociales para estudiantes universitarios de alto potencial académico" presenta un estudio con diseño documental sobre las habilidades sociales de estudiantes universitarios y frente a ello proponer un curso especial para desarrollarlas a partir de su alta potencialidad académica.

El artículo titulado "Clima Organizacional en las Instituciones Educativas de Santa Marta, Colombia" desarrollado por Nair Hincapié Parejo, de la Institución Educativa Distrital Beatriz Gutiérrez de Vives y del Colegio El Divino Niño. Santa Marta, Colombia Edison Orellana Orellana y Carlos Orellana Orellana, estos últimos adscritos a la Universidad Católica de Cuencas. Ecuador, tuvo como objetivo determinar el clima organizacional en las instituciones escolares de Santa Marta, Colombia, con la finalidad de aportar estrategias, soluciones que fomenten un mejor funcionamiento y relaciones óptimas entre el personal y gerentes, líderes o personal directivo, en pro de un mejor desempeño laboral y satisfacción por los logros cumplidos.

Finaliza esta edición con el ensayo presentado por Olga Piedad Aguirre, de la Institución Educativa Bello Horizonte de la ciudad de Medellín, Colombia, titulado "Del conflicto al postacuerdo: Un proceso educativo", aborda la construcción de ciudadanía como eje para consolidar una cultura de paz, teniendo como premisa que para escindir las raíces de la violencia es fundamental y necesario la transformación de las nuevas generaciones, con propuestas pedagógicas que se validen en los contextos y ámbitos, como ejercicios democráticos, éticos y responsables

Amigos lectores, disfruten esta edición de nuestra revista multidisciplinaria ORATORES. 